\title{
Photoinhibition of photosynthesis in Antarctic lichen Usnea antarctica. II. Analysis of non-photochemical quenching mechanisms activated by low to medium light doses
}

\author{
Petra Očenášová , Miloš Barták, Josef Hájek \\ Department of Plant Physiology and Anatomy, Institute of Experimental Biology, \\ Masaryk University, Kamenice 5, 62500 Brno, Czech Republic
}

\begin{abstract}
The paper focus sensitivity of an Antarctic lichen Usnea antarctica to photoinhibition studied under controlled laboratory conditions. Main emphasis was given to the analysis of quenching mechanisms, i.e. deexcitation pathways of absorbed light energy exploited in non-photochemical processes. Thalli of $U$. antarctica were collected at the James Ross Island, Antarctica (57 $\left.52^{\prime} 57^{\prime \prime} \mathrm{W}, 63^{\circ} 48^{\prime} 02^{\prime \prime} \mathrm{S}\right)$ and transferred in dry state to the Czech Republic. After rewetting in a laboratory, they were exposed to medium light intensities $\left(300,600\right.$ and $1000 \mu \mathrm{mol} \mathrm{m}^{-2} \mathrm{~s}^{-1}$ of photosynthetically active radiation) for $6 \mathrm{~h}$. Before and during photoinhibitory treatments, chlorophyll fluorescence parameters, photoinhibitory (qI), state 1-2 transition (qT), and energy-dependent quenching (qE) in particular were measured to evaluate dose- and time-dependent changes in these parameters. The results showed that among the components forming non-photochemical quenching ( $\mathrm{qN}$ ), $\mathrm{qI}$ contributes to the largest extent to $\mathrm{qN}$, while $\mathrm{qE}$ and $\mathrm{qT}$ contribute less. This finding differs from our earlier studies made in a short term-, and high lighttreated $U$. antarctica that found $\mathrm{qE}$ together with $\mathrm{qI}$ is the most important part of nonphotochemical quenching. Possible explanation is that photoinhibition in PS II in U. antarctica, when induced by low to medium light, activates $\mathrm{qE}$ to only limited extend and for a relatively short time (tens of minutes). With prolonged high light treatment lasting several hours, $\mathrm{qE}$ tends to be reduced to the values close to zero and $\mathrm{qI}$ then forms a major part of $\mathrm{qN}$.
\end{abstract}

Key words: photoinhibitory quenching, state1-2 transition quenching, energy-dependent quenching

Abbreviations: $\mathrm{F}_{\mathrm{V}} / \mathrm{F}_{\mathrm{M}}$ - potential photosynthetic quantum yield of photosystem II, $\Phi_{\mathrm{PSII}}$ effective photosynthetic quantum yield of photosystem II, NPQ/qN - non-photochemical quenching, qE - energy-dependent quenching, qI - photoinhibitory quenching, qT - state 1-2 transition quenching

DOI: $10.5817 / \mathrm{CPR} 2014-1-10$

Received March 25, 2014, accepted August 22, 2014.

"Corresponding author: Petra Očenášová <p.ocenasova@gmail.com>

Acknowledgements: The authors are grateful to CzechPolar project for the infrastructure provided during field collection of samples in Antarctica and laboratory measurements. 


\section{Introduction}

Photoinhibition of photosynthesis is defined as light dependent and slowly reversible retardation of photosynthesis, independent of any developmental change. Functional consequences of photoinhibition of photosynthesis are a reduction in the maximum quantum yields for $\mathrm{CO}_{2}$ uptake and oxygen evolution (Long et al. 1994). In photosynthetic apparatus, chloroplastic pigment-protein complexes in particular, photoinhibition is understood as any change to photosystem II (PS II) and/or molecular components of photosynthetic electron transport chain that, due to excess light absorbed in chlorophyll molecules, reduce effectivity of photosystem II functioning. Some studies exploiting chlorophyll fluorescence approach, however, have used photoinhibition to mean photooxidative damage to PS II.

In lichens and mosses, due to their poikilohydric nature, photoinhibition is not studied as frequently as in higher plants since unstable and, thanks to environmental factors rapidly changing hydration status of lichen thalli affect photosynthetic processes and thus complicate measurements. Therefore, majority of studies of photoinhibition in the lichens and mosses are made under controlled laboratory conditions when hydration status of lichen thalli is kept constant. Such studies have shown that sensitivity of lichens to photoinhibition is species-specific and related to algal/cyanobacterial photobiont (DemmigAdams et al. 1990a) and capacity of interconversion of xanthophyll cycle pigments, i.e. zeaxanthin formation (Demmig-Adams et al. 1990b). Other factors affecting sensitivity of lichens to photoinhibition are prevailing light environment of the habitat (Gauslaa et Solhaug 1996). Recently, physiological background of photoprotective mechanisms in PS II in photoinhibited chlorolichens is studied (Heber et al. 2000). The studies point out similarities of quenching mechanisms activated in desiccating and photoinhibited lichens (Heber 2008), their symbiotic algae in particular (Wieners et al. 2012).

Several field experiments have been made to study photoinhibition in Antarctica using both gas exchange and chlorophyll fluorescence approach in the field (e.g. Kappen et al. 1998). Among them, the study made on Antarctic mosses (Lovelock et al. 1995) pointed out reversible photoinhibition in an Antarctic moss measured at wet state. However, field studies made on Antarctic lichens could hardly distinguish between limitation of photosynthetic processes related to thallus dehydration and progressive photoinhibition because the processes co-occur simultaneously. That was why the photoinhibition of Antarctic lichens is studied under constant thallus hydration in laboratorybased facilities. Lichens from open, sunny habitats have generally a high capacity to cope with a short-term high light stress. In laboratory studies, chlorophyll fluorescence technique is used to determine extent of PS II functioning. Slow chlorophyll fluorescence kinetics supplemented with quenching analysis is used more frequently (e.g. Barták et al. 2004, Singh et al. 2013) then fast chlorophyll fluorescence transient (OJIP - see e.g. Maksimov et al. 2014). In studies focused on photoinhibition that exploit chlorophyll fluorescence kinetics supplemented with quenching analysis, lichens show a rapid recovery (in terms of hours) of functioning of PS II to pre-photoinhibitory status after termination of high light stress as shown for Usnea antarctica in our previous study (Barták et al. 2012).

The main aim of this study is to compare the negative effects of short- and long-term exposition of Usnea antarctica caused by high light using a chlorophyll fluorescence approach. In previous paper (Barták et al. 2012), we focused on negative effects of a short-term photoinhibitory 
treatment on PS II, $\mathrm{F}_{\mathrm{V}} / \mathrm{F}_{\mathrm{M}}$, $\Phi_{\mathrm{PSII}}$ in particular. In the follow-up study, we paid attention to the activation of physiological mechanisms forming non-photochemical quenching of absorbed light energy. We hypothesised that photoinhibitory quenching (qI) would be gradually activated with the time of photoinhibitory treatment. We also expected dependency of qI on light dose, i.e. extent of $\mathrm{qI}$, its proportion to $\mathrm{qN}$ should increase with photoinhibitory light dose. We also hypothesised that contribution of state 1-2 transition (qT), and energy-dependent quechning $(\mathrm{qE})$ to $\mathrm{qN}$ would be much lower than that of qI. For experimental photoinhibitory treatment, we have chosen low to medium light intensities so that critical light under which $U$. antarctica activates mechanisms resulting in qI increase could be identified. In contrast to other studies made on Antarctic lichens (e.g. Barták et al. 2003) that focused rather short-term photoinhibitory treatment and light doses about 2000 $\mu \mathrm{mol} \mathrm{m} \mathrm{m}^{-2}$, we used low to medium light intensities and photoinhibitory treatment as long as $6 \mathrm{~h}$.

\section{Material and Methods}

Before experimental HL treatment, thalli of $U$. antarctica (see Fig. 1) were rehydrated from dry state by regular spraying (each $12 \mathrm{~h}$ ) by a demineralized water for $72 \mathrm{~h}$. The thalli were placed into Petri dishes between two small sheets of paper, kept at $5^{\circ} \mathrm{C}$ and exposed to PAR of $10 \mu \mathrm{mol} \mathrm{m} \mathrm{m}^{-2} \mathrm{~s}^{-1}$ and sprayed each $12 \mathrm{~h}$. For experiments, thalli showing highest values of effective quantum yield of photosynthetic processes in PS II (preexperiment, data not shown) were selected.

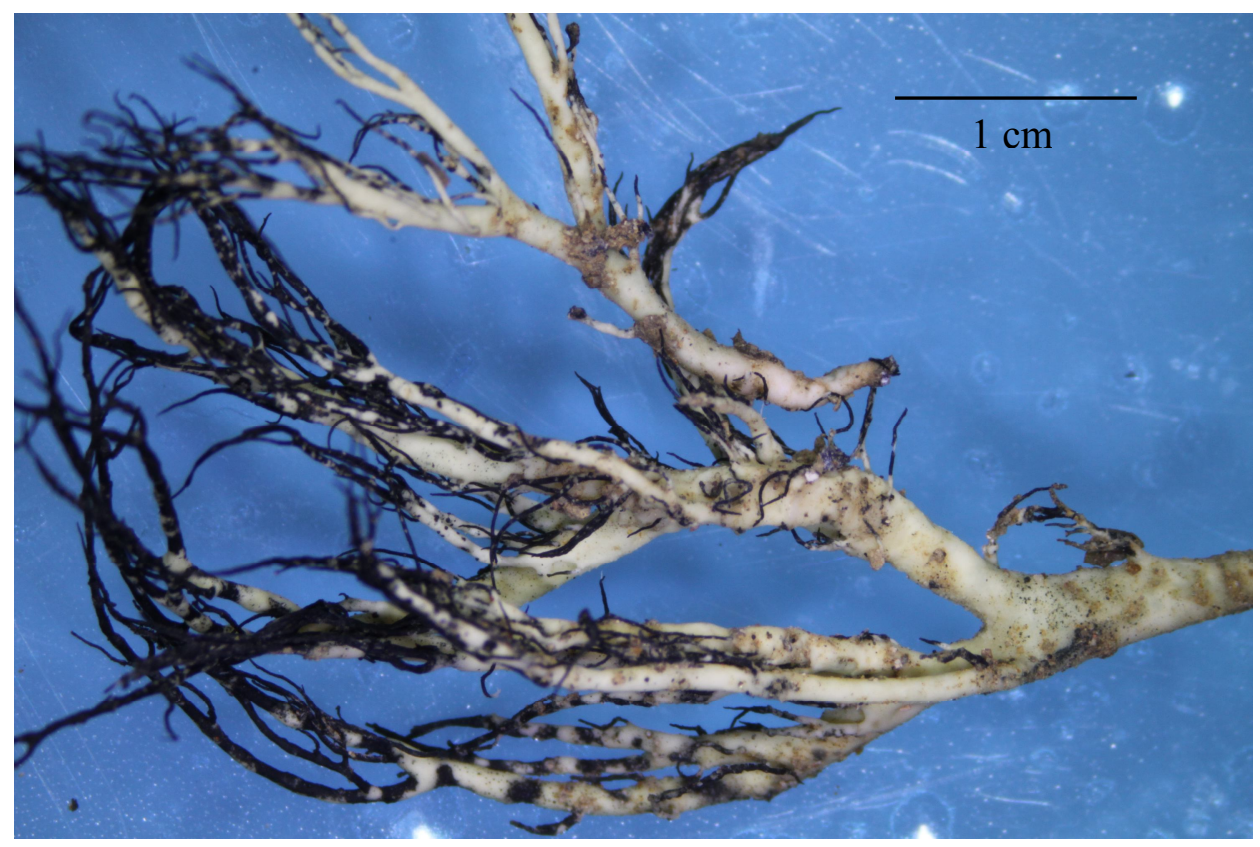

Fig. 1. Detailed photo of Usnea antarctica - a lichen with fruticose thallus morphology. Photo by M. Barták. 


\section{Long-term photoinhibitory treatment}

In the long-term experiment, three different irradiances of 300,600 and $1000 \mu \mathrm{mol}$ $\mathrm{m}^{-2} \mathrm{~s}^{-1}$ of photosynthetically active radiation were used. Photoinhibitory treatment was provided by a cold LED light source (Technical University, Brno, Czech Republic). Wet $U$. antarctica thalli were placed into a Petri dish with an outer jacket cooled by ice grains so that thallus temperature was kept constant at $5^{\circ} \mathrm{C}$ (measured by a $\mathrm{HOBO}$ thermocouple and datalogger, Onset Computers, USA) during photoinhibitory treatment. Similarly to previous experiments (Barták et al. 2003, Barták et al. 2012), lichen thalli were oriented horizontally in the Petri dish, i.e. perpendicularly to incident light. Individual thalli were arranged in parallel, in such a way that between-thalli shading was avoided. The thalli were exposed to the above-specified light doses for $360 \mathrm{~min}$. Within the period, chlorophyll fluorescence parameters were measured repeatedly ( 8 times) so that time courses of individual chlorophyll fluorescence parameters (see below) characterizing lichen responses to the three experimental light treatment could be evaluated.

\section{Chlorophyll fluorescence parameters}

Before Chl fluorescence measurements, individual $U$. antarctica thalli were placed into a predarkening clip and kept in dark for $10 \mathrm{~min}$. to reach full reoxidation of PS II core. For chlorophyll fluorescence measurements, a PAM-2000 (Heinz Walz, Germany), was used. To derive chlorophyll fluorescence parameters, non-photochemical quenching and its components in particular, a method of slow Kautsky kinetics supplemented with saturation pulses was used (see Fig. 2) - for details see Roháček et al. (2008). To evaluate components of non-photochemical quenching, repetitive pulses of saturation light were applied in $30 \mathrm{~s}$ interval, after actinic light was switched off. For $\mathrm{F}_{\mathrm{M}}{ }^{\prime \prime}$, the last saturation pulse applied after $300 \mathrm{~s}$ in dark was used. These measurements were taken repeatedly. To assess the effect of dose and duration of photoinhibitory light treatment on non-photochemical quenching of absorbed light energy in PS II, and its components $\mathrm{qE}$, qI, and qT (for definition, see Krause et Weis 1991) were evaluated. For qE, qI, and qT calculation, Eqns. 3-5 (Roháček 2002, 2010) were used.

$$
\begin{array}{lr}
\mathrm{NPQ}=\left(\mathrm{F}_{\mathrm{M}}-\mathrm{F}_{\mathrm{M}}{ }^{\prime}\right) / \mathrm{F}_{\mathrm{M}}{ }^{\prime} & \text { Eqn. } 1 \\
\mathrm{q}_{\mathrm{N}}=\left(\mathrm{F}_{\mathrm{M}}-\mathrm{F}_{0}\right)-\left(\mathrm{F}_{\mathrm{M}}{ }^{\prime}-\mathrm{F}_{0}{ }^{\prime}\right) /\left(\mathrm{F}_{\mathrm{M}}-\mathrm{F}_{0}\right) & \text { Eqn. } 2 \\
\mathrm{q}_{\mathrm{E}}=2 *\left(\mathrm{~F}_{\mathrm{M}}{ }^{\prime \prime}-\mathrm{F}_{0}{ }^{\prime \prime}\right)-\left(\mathrm{F}_{\mathrm{M}}{ }^{\prime}-\mathrm{F}_{0}{ }^{\prime}\right) /\left(\mathrm{F}_{\mathrm{M}}-\mathrm{F}_{0}\right) & \text { Eqn. } 3 \\
\mathrm{q}_{\mathrm{I}}=\left(\mathrm{F}_{\mathrm{M}}-\mathrm{F}_{0}\right)-\left(\mathrm{F}_{\mathrm{M}}{ }^{\prime \prime}-\mathrm{F}_{0}{ }^{\prime}{ }^{\prime}\right) /\left(\mathrm{F}_{\mathrm{M}}-\mathrm{F}_{0}\right) & \text { Eqn. } 4 \\
\mathrm{q}_{\mathrm{T}}=\mathrm{q}_{\mathrm{N}}-\mathrm{q}_{\mathrm{E}}-\mathrm{q}_{\mathrm{I}} & \text { Eqn. } 5
\end{array}
$$

where $\mathrm{F}_{0} / \mathrm{F}_{0}{ }^{\prime}$ is minimum (background) chlorophyll fluorescence induced by a weak light in dark-/light-adapted sample, $\mathrm{F}_{\mathrm{M}}$ is maximum chlorophyll fluorescence reached during saturation pulse applied on dark-adapted sample, $\mathrm{F}_{\mathrm{M}}{ }^{\prime}$ is chlorophyll fluorescence level reached during a saturation pulse applied on light-adapted sample (actinic light on), $\mathrm{F}_{\mathrm{M}}{ }^{\prime \prime}$ is chlorophyll fluorescence level reached during saturation pulse applied on sample after switching off actinic light. For calculations of qN, NPQ and qI during photoinhibitory treatment, initial (prephotoinhibitory) $F_{M}$ value of was used (Barták et al. 2003). For $F_{M}{ }^{\prime \prime}$ value, the last saturation pulse was applied after the sample was for $300 \mathrm{~s}$ in dark was used. 


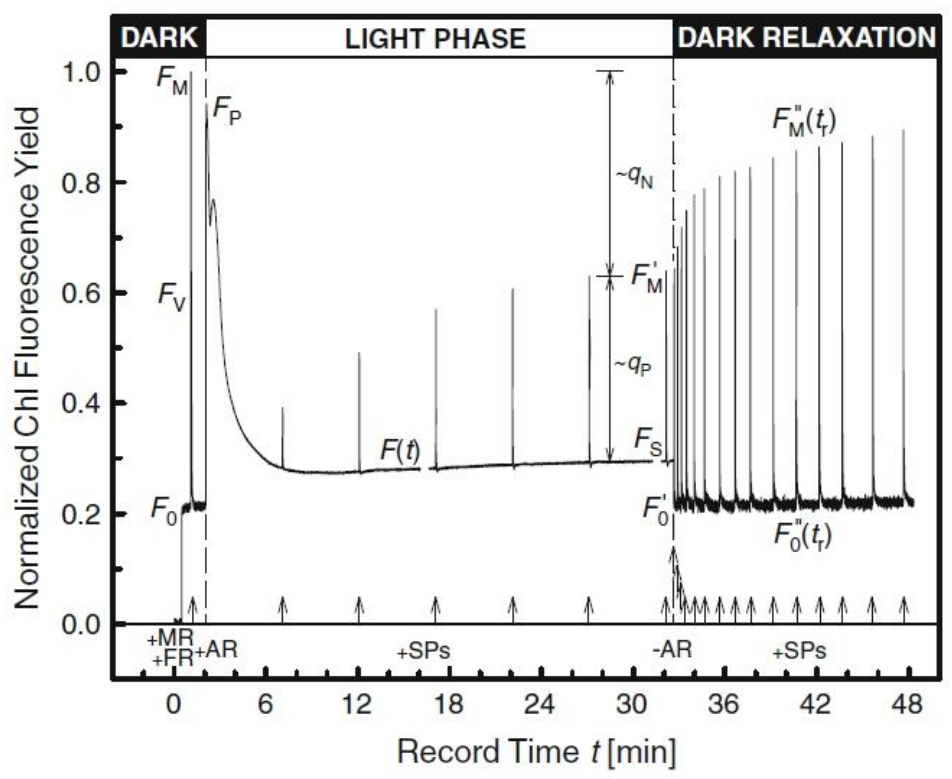

Fig. 2. Slow chlorophyll fluorescence curve with indication pulses and values of chlorophyll fluorescence used in calculations of non-photochemical quenching and its components (qI, qT, and qE). Source: Roháček (2010).

\section{Statistical data analysis}

Time courses of chlorophyll fluorescence parameters were processed by an analysis of variance (ANOVA, Statistica, StatSoft, Inc., USA). Statistical significance was evaluated by a Post-hoc test (Newman-Keuls) on 95\% level of significance.

\section{Results and Discussion}

As expected, potential quantum yield of PS II photochemical processes $\left(\mathrm{F}_{\mathrm{V}} / \mathrm{F}_{\mathrm{M}}\right)$ decreased in an exponential manner (see Fig. 3) with time of exposition to photoinhibitory light. The highest decrease of $F_{V} / F_{M}$ was found in the $1000 \mu \mathrm{mol} \mathrm{m} \mathrm{m}^{-2} \mathrm{~s}^{-1}$ treatment throughout the whole exposition time. Irrespective of treatment, final $\mathrm{F}_{\mathrm{V}} / \mathrm{F}_{\mathrm{M}}$ value was found as low as $0.22-0.35$ indicating substantial photoinhibition of PS II after 6 h-lasting light treatment. For Usnea antarctica, earlier study of Barták et al. (2003) reported substantial decrease of $\mathrm{F}_{\mathrm{V}} / \mathrm{F}_{\mathrm{M}}$ found immediatelly after a shortterm photoinhibitory treatment, as well as their fast recovery. In the study, fast phase of recovery (lasting typically $30 \mathrm{~min}$.) was attributed to structural changes in PS II and LHCs and the effects of antioxidative mechanisms. Slow phase of recovery (lasting from tens to hundreds of minutes) was attributed to resynthetic processes in a thylakoid membrane that repair damaged components of PS II an LHCs. Long-term photoinhibition exploiting the exposition of wet lichen thalli to high light for the periods longer than $1 \mathrm{~h}$, has been applied in Central European (Barták et al. 2008) but not yet in Antarctic lichens. 


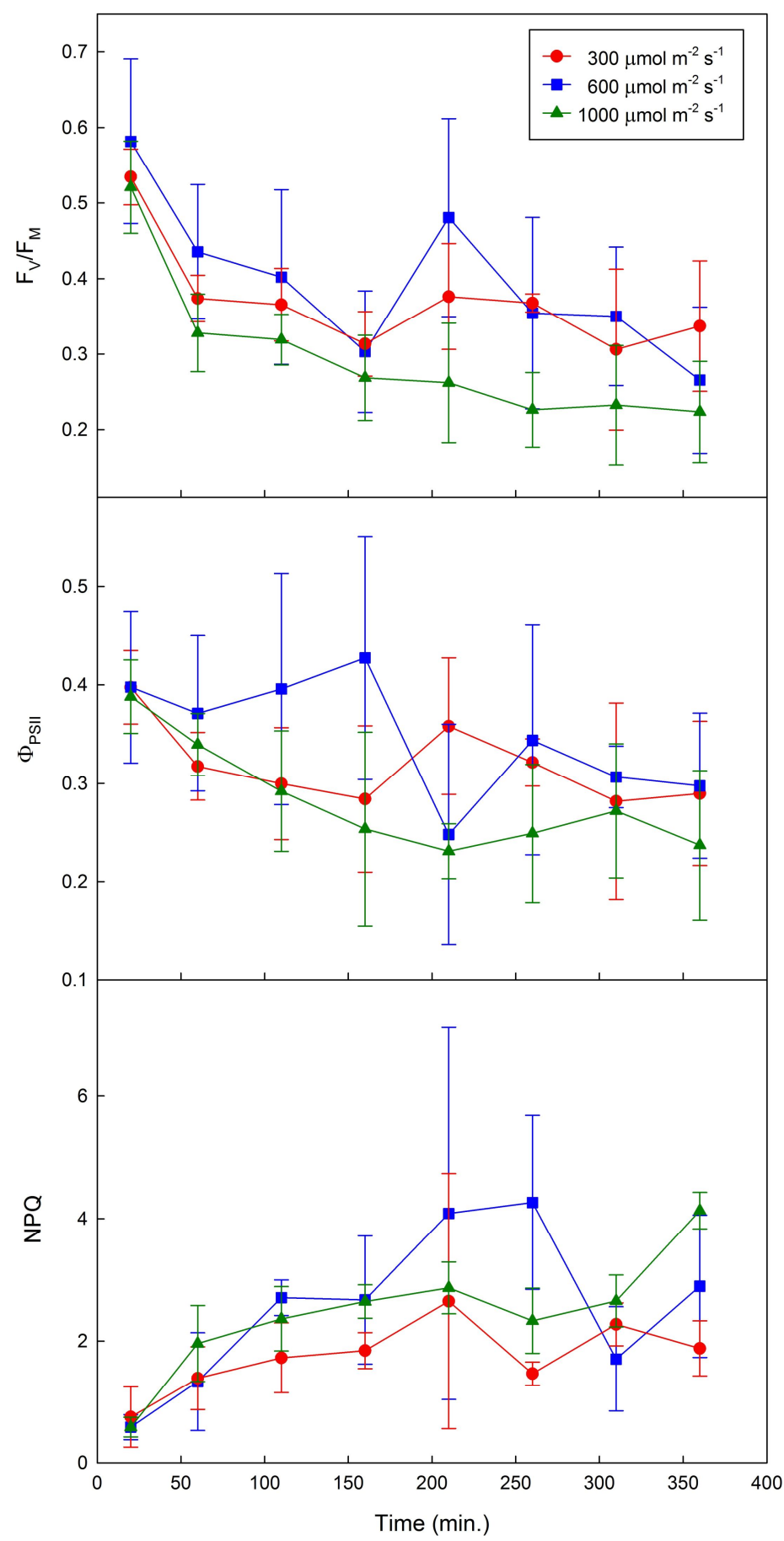

Fig. 3. Time course of $F_{V} / F_{M}$ (potential photosynthetic quantum yield of photosystem II), $\Phi_{\text {PSII }}$ (effective photosynthetic quantum yield of photosystem II) and NPQ (non-photochemical quenching) in Usnea antarctica in response to 3 photoinhibitory treatment. 


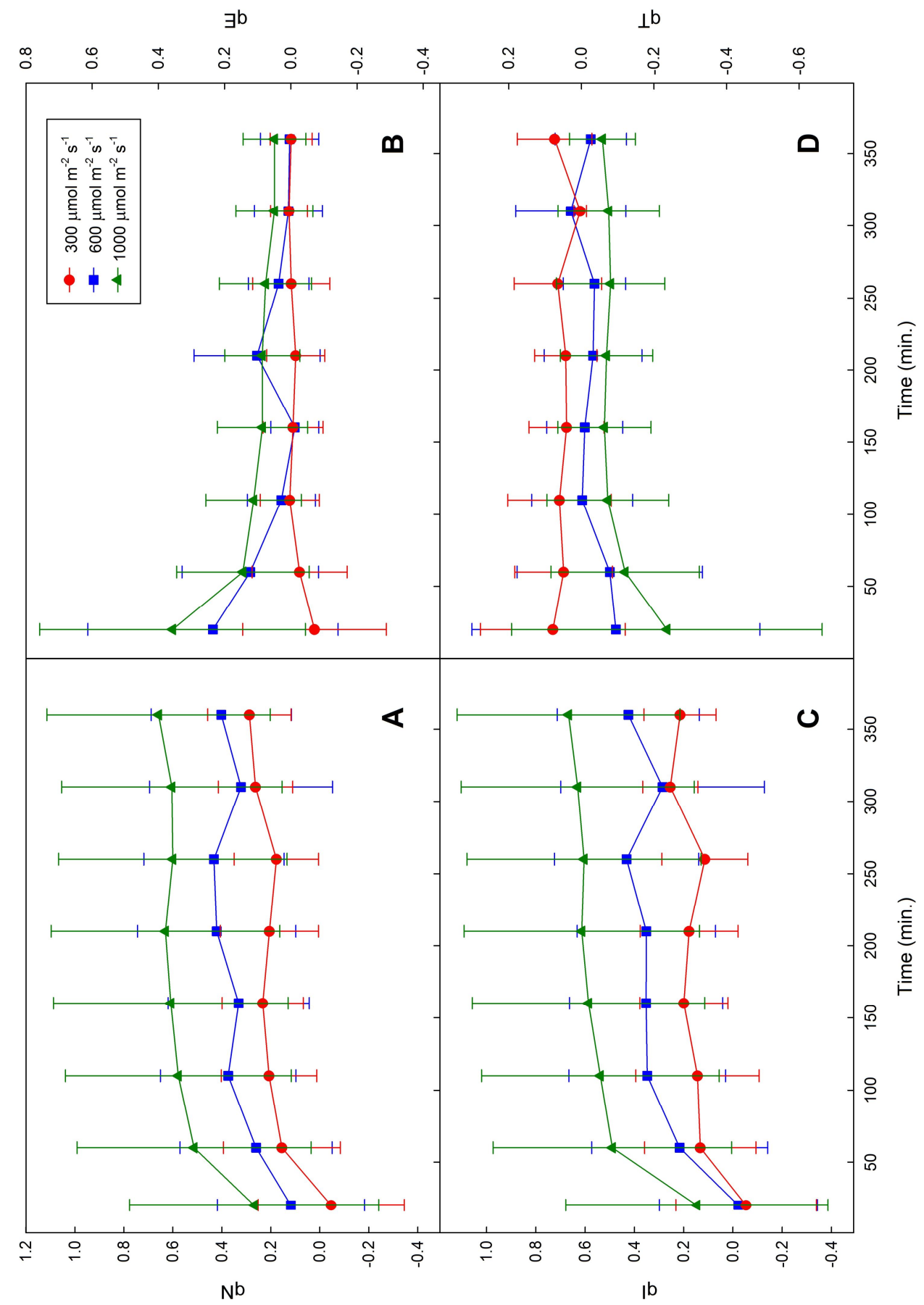

Fig. 4. Time course of $\mathrm{qN}$ (non-photochemical quenching), $\mathrm{qE}$ (energy-dependent quenching), qI (photoinhibitory quenching) and qT (state 1-2 transition quenching) in Usnea antarctica in response to 3 photoinhibitory treatment. 
Non-photochemical quenching, both NPQ and qN increased with high light treatment, however the shape of the relationships of NPQ/qN to time of light treatment slightly differed. The rate of initial $\mathrm{qN}$ increase was higher than that of NPQ within the first $60 \mathrm{~min}$. of light treatment. In both parameters, more or less equilibrated value was reached after 210 min. exposition to experimental light treatments indicating that such time is required to activate and balance all physiological mechanisms involved into photoprotection of photosynthetic apparatus of lichen symbiotic alga Trebouxia sp. Formation of zeaxanthin from violaxanthin is one of them that is considered as an early response of photosynthetic apparatus to high-light stress. It is associated with formation of transthylakoidal pH gradient when PS II are overenergized due to excess light. These changes lead to an increase in energydependent quenching ( $\mathrm{qE}$ ). In our study, $\mathrm{qE}$ showed generaly increased values only in the first $120 \mathrm{~min}$. of high light treatments (see Fig. 4B), then decreased to more or less constant value close to zero, indicating that the light doses used in this study did not cause full and long-term activation of violaxantin to zeaxanthin conversion. Thus, qE-attributed photoprotective mechanisms were not exploited when 300,600 and $1000 \mu \mathrm{mol} \mathrm{m} \mathrm{m}^{-2}$ of PAR were used. Such conclusion can be supported by the data of Balarinová et al. (2014) who reported only small change in glutathione content, another photoprotective mechanism, in $U$. antarctica exposed to the same high light treatments. Higher light doses (typically of about $2000 \mu \mathrm{mol}$

\section{Concluding remarks}

As shown in this and previous study (Barták et al. 2012), hydrated U. antarcti$c a$ is resistant to both short-term (strong) and long-term (low to medium light) photoinhibitory treatments. Such a resistance $\mathrm{m}^{-2} \mathrm{~s}^{-1}$ of PAR), however, lead to a dramatic decrease of glutathione content in lichens due to light-dependent glutathione degradation to glutamylcysteine (Barták et al. 2004, Vráblíková et al. 2005).

State one-state two transition quenching (qT) was found more or less constant throughout the period of high light treatments showing the values close to zero (see Fig. 4D). This indicated that the light doses used in our study did not cause activation of non-photosynthetic energy transport from PS II to PS I via detached of energized LHCs from PS II. Such mechanism, i.e. $\mathrm{qT}$, generally only makes a small contribution to overal non-photochemical quenching and is typical for low light doses specifically (Maxwell et Johnson 2000). In studies devoted to photoinhibition in lichens, qT it is typically evaluated together with photoinhibitory quenching qI (i.e. qT+I, see e.g. Barták et al. 2003).

Photoinhibitory quenching (qI) exhibited a rise during high light treatment, most rapid and apparent at $1000 \mu \mathrm{mol} \mathrm{m} \mathrm{m}^{-2} \mathrm{~s}^{-1}$ of PAR within the first $60 \mathrm{~min}$. of the treatment (see Fig. 4C). At the end of exposition to high light, qI values were found significantly higher $(\mathrm{qI}=0.65)$ in $U$. antarctica treated by $1000 \mu \mathrm{mol} \mathrm{m} \mathrm{m}^{-2} \mathrm{~s}^{-1}$ than in other two treatments. These results suggest that the changes in structure and functioning of PS II induced by photoinhibitory treatment were dose- dependent as hypothesized. Irrespective of high light treatment, qI formed dominant part of total $\mathrm{qN}$ indicating that the other two mechanisms, i.e. $\mathrm{qE}$ and $\mathrm{qT}$ were much less involved into photoprotection of $U$. antarctica exposed to physiological PAR doses.

might be attributed to effective dissipation of absorbed light energy. The dissipation involves xanthophyll pigments cycle and also zeaxanthin-independent quenching of absorbed light energy by strong sinks lead- 
ing to heat dissipation. Another cause for high resistance of $U$. antarctica to photoinhibition is a presence of antioxidative enzymes and substrates in lichen thalli, glutathione in particular (Balarinová et al. 2014, Gasulla et al. 2012). Further research involving fluorometric, biochemical and molecular-biology approaches is required to evaluate contribution and particular importance of (1) energy dissipation and (2) activity of antioxidants to effective photoprotection in $U$. antarctica and/or other Antarctic lichens.

\section{References}

Balarinová, K., Barták, M., Hazdrová, J., HáJek, J. and JílkovÁ, J. (2014): Changes in photosynthesis, pigment composition and glutathione contents in two Antarctic lichens during a light stress and recovery. Photosynthetica: submitted/accepted.

BARTÁK, M., VRÁBlíkovÁ, H. and HÁJeK, J. (2003): Sensitivity of photosystem 2 of Antarctic lichens to high irradiance stress: Fluorometric study of fruticose (Usnea antarctica) and foliose (Umbilicaria decussata) species. Photosynthetica, 41: 497-504.

Barták, M., Hájek, J., VRÁblíková, H. and DubovÁ, J. (2004): High-light stress and photoprotection in Umbilicaria antarctica monitored by chlorophyll fluorescence imaging and changes in zeaxanthin and glutathione. Plant Biology, 6: 333-341.

Barták, M., VráblíkovÁ-Cempírková, H., Štepigová, J., HÁJek, J., VÁczi, P. and VečeřovÁ, K. (2008): Duration of irradiation rather than quantity and frequency of high irradiance inhibits photosynthetic processes in the lichen Lasallia pustulata. Photosynthetica, 46: 161-169.

BARTÁK, M., HÁJeK, J. and OČENÁŠOvÁ, P. (2012): Photoinhibition of photosynthesis in Antarctic lichen Usnea antarctica. I. Light intensity- and light duration-dependent changes in functioning of photosystem II. Czech Polar Reports, 2: 42-51.

Demmig-Adams, B., Adams III, W. W., Green, T. G. A., Czygan, F. C. and Lange, O. L. (1990a): Differences in the susceptibility to light stress in two lichens forming a phycosymbiodeme, one partner possessing and one lacking the xanthophyll cycle. Oecologia, 84: 451-456.

Demmig-Adams, B., Máguas, C., Adams III, W. W., Meyer, A., Kilian, E. and Lange, O. L. (1990b): Effect of high light on the efficiency of photochemical energy conversion in a variety of lichen species with green and blue-green phycobionts. Planta, 180: 400-409.

Gasulla, F. Herrero, J., Esteban-Carrasco, A., Ros-Barceló, A., Barreno, E., Zapata, J. M. and GuÉRA, A. (2012): Photosynthesis in Lichen: Light Reactions and Protective Mechanisms. In: M. M. Najafpour (ed.): Advances in Photosynthesis - Fundamental Aspects. Publisher: InTech, Chapter 8, pp. 149-174.

Gauslaa, Y., Solhaug, K. A. (1996): Differences in the susceptibility to light stress between epiphytic lichens of ancient and young boreal forest stands. Functional Ecology, 10: 344-354.

Heber, U., Bilger, W., Bligny, R. and Lange, O. L. (2000): Phototolerance of lichens, mosses and higher plants in an alpine environment: analysis of photoreactions. Planta, 211: 770-780.

HEBER, U. (2008): Photoprotection of green plants: a mechanism of ultra-fast thermal energy dissipation in desiccated lichens. Planta, 228: 641-650.

Kappen, L., Schroeter, B., Green, T. G. A. and Seppelt, R. D. (1998): Chlorophyll a fluorescence and $\mathrm{CO} 2$ exchange of Umbilicaria aprina under extreme light stress in the cold. Oecologia, 113: 325-331.

Krause, G. H., Weis, E. (1991): Chlorophyll Fluorescence and Photosynthesis - the Basics. Annual Review of Plant Physiology and Plant Molecular Biology, 42: 313-349.

LonG, S. P., Humpries, S. and Falkowski, P. G. (1994): Photoinhibition of photosynthesis in nature. Annual Review of Plant Physiology and Plant Molecular Biology, 45: 633-662.

Lovelock, C. E., Jackson, A. E., Melick, D. R. and Seppelt, R. D. (1995): Reversible Photoinhibition in Antarctic Moss during Freezing and Thawing. Plant Physiology, 109: 955961. 
Maksimov, E. G., Schmitt, F. J., Tsoraev G. V., Ryabova A. V., Friedrich T. and Paschenko, V.Z. (2014): Fluorescence quenching in the lichen Peltigera aphthosa due to desiccation. Plant Physiology and Biochemistry, 81: 67-73.

MaXwell, K., Johnson, G. N. (2000): Chlorophyll fluorescence - a practical guide. Journal of Experimental Botany, 51: 659-668.

ROHÁČEK, K. (2002): Chlorophyll fluorescence parameters: the definitions, photosynthetic meaning, and mutual relationships. Photosynthetica, 40: 13-29.

RoHÁČEK, K. (2010): Method for resolution and quantification of components of the nonphotochemical quenching (qN). Photosynthesis Research, 105: 101-113.

ROHÁČEK, K., SOUKUPOVÁ, J. and BARTÁK, M. (2008): Chlorophyll fluorescence: A wonderful tool to study plant physiology and plant stress. In: B. Schoefs (eds.): Plant Cell Compartments Selected Topics. Research Signpost, Kerala - India, pp. 41-104.

Singh, R., Ranjan, S., Nayaka, S., Pathre, U. V. and Shirke, P. A. (2013): Functional characteristics of a fruticose type of lichen, Stereocaulon foliolosum Nyl. in response to light and water stress. Acta Physiologiae Plantarum, 35: 1605-1615.

VRÁBLíKOVÁ, H., BARTÁK, M. and WÖNISCH, A. (2005): Changes in glutathione and xanthophyll cycle pigments in high light-stressed lichens Umbilicaria antarctica and Lasallia pustulata. Journal of Photochemistry and Photobiology B: Biology, 79: 35-41.

Wieners, P. C., Mudimu, O. and Bilger, W. (2012): Desiccation-induced non-radiative dissipation in isolated green lichen algae. Photosynthesis Research, 113: 239-247. 